\title{
Democracy and Entitlements in Sri Lanka The 1970s crisis over university admission
}

\author{
Nira Wickramasinghe \\ Université de Leyde
}

From the early 1930s, when the Donoughmore Commission on constitutional reform inspired by Fabian ideas brought about an unprecedented form of self-government coupled with universal suffrage to the crown colony of Ceylon making it the first country in Asia to enjoy this right, people of the island began to look at the state in a new light. The state - which was until then an institution to which they paid taxes and that they occasionally petitioned - became entrenched in their imaginary as a space of utopian possibility, a source of justice, redress and resources that could be distributed at will, thus touching and transforming the core of their lives. Jayadeva Uyangoda has lucidly articulated how the pedagogical mission of the state and peoples' expectations are still bound in a tight social contract:

'The centrality of the state in regulating our social existence became particularly prominent with the postcolonial welfare state. Consequently, ours has become an intensely paternalistic and interventionist state where for education, employment, food and clothing health, transport and even for taking revenge on an adversary the state is expected to step in as the supreme regulatory agency, 164 .

After 1956, however, when the Sinhala language was made the official language (Sinhala Only Act 33 of 1956) and over the following decades, a growing perception of the state as bestowing public goods selectively began to emerge, challenging previous views and breeding mistrust between communities. This was the predicament of what the Sinhalese nationalist ideologue Gunadasa Ameresekere called the 'post-1956 generation': Sinhalese and Tamil youth educated in two separate language streams growing to think and feel as two distinct communities.

The 1970s university admission schemes represent a crucial moment in the process of transformation of the way the state was perceived, no longer as a harbinger of social justice but as an impediment to some peoples' very 'capacity to aspire' to borrow Appadurai's words . This negative perception of the state was not shared by all its citizens. But as educational policies were seen by some to stray from principles of merit and fairness, they served more than any other later policies to vindicate non-believers, those who searched proof for the doubts they harboured about the impartiality of the state in its dispensation of social justice. The changes introduced in the criteria for university admission read by its adversaries as an unfair form of affirmative action vis-à-vis the Sinhalese community led to a permanent crisis situation

\footnotetext{
${ }^{1}$ Jayadeva Uyangoda, 'Political Dimensions of Youth Unrest in Sri Lanka' in ed. S.T. Hettige, Unrest or Revolt. Some Aspects of Youth Unrest in Sri Lanka, Colombo Goethe Institute and American Studies Association, 1992, p. 35-38
} 
in higher education. Their impact, as we will see, was much more complex and differentiated regionally, ethnically and class wise but this hardly mattered. Equally harsh measures put in place in recruitment patterns where less than 10 percent of places in central government were given to Tamils were not condemned in the same vein ${ }^{165}$. Over time 'standardisation' - the name of the scheme - acquired an after-life and symbolic weight that bore little relation to its real purpose or impact on society.

In 1970 a Left of center United Front headed by Sirimavo Bandaranaike gained power. This coalition of the Sri Lanka Freedom Party (SLFP) as the major partner and the Lanka Sama Samaja Party (LSSP) and the Communist Party (CP) remained in office until 1975 when the minor parties left. In 1972 the government introduced a new authochtonous constitution that gave Buddhism, the religion of the vast majority of the Sinhalese, the foremost place, concentrated power in the legislature and the prime-ministerial executive and eradicated Section 29 of the Soulbury constitution, an article that had afforded some protection to minority communities against discrimination. It is in this context that new policies that invoked the principle of compensatory justice in favour of underprivileged social and regional groups that belonged mainly to the Sinhalese majority community and aimed at righting past injustices must be understood.

'Nationalism' and anti-Tamil feelings have often been identified as the prime 'causes' of the changes in the selection to universities both in scholarly work as well as in the common perception of Sri Lankan Tamils. Tamils, it is still widely believed, were "being systematically squeezed out of higher education, ${ }^{, 166}$. This paper complicates the story as it links policies of standardization less to nationalism than to an understanding of democracy that originates in the late colonial period founded on the premises that the democratic state has a responsibility to correct imbalances that exist in society between communities and classes and distribute entitlements in the fairest manner. This is spelt out in the Budget speech on 1970/1971 which was presented by the LSSP Finance Minister, Colvin R. de Silva. One of the objectives is stated as:

'To maintain those social welfare measures which are an integral part of our social fabric and to take all such steps as the situation demands to provide the necessities of life at reasonable prices to the mass of our people' ${ }^{167}$.

Why did a seemingly reasonable purpose fail to yield the expected results and end up as a straw man for all critiques of Sinhala Buddhist majoritarianism?

\footnotetext{
${ }^{2}$ S.W.R.D. de A. Samarasinghe, 'Ethnic representation in Central Government Employment and Sinhala-Tamil relations in Sri Lanka 1948-1981' in eds. Robert B. Goldman and A.J. Wilson, From Independence to Statehood, London: Frances Pinter, 1984, p. 182

${ }^{166}$ Walter Schwartz, 'Tamils of Sri Lanka', London: Minority Rights Group, 1975, p. 12

${ }^{4}$ Cited in Patricia J.Alailima, 'Social Policy in Sri Lanka' in ed . W.D. Lakshman, Dilemmas of development. Fifty Years of Economic Change in Sri Lanka, Sri Lanka Association of Economists, 1997, p. 150.
} 
This paper will first analyze the double edged effects of the 1970s policies of affirmative action created with the dual purpose of imparting social justice to groups that lagged behind and after the tears and bruises of the 1971 leftist JVP revolt, of cementing the majority Sinhalese people as a unified political community dependent on a caring state. In the second section we will argue that the affirmative action educational schemes of the 1970s that have been emotionally and politically interpreted as a break or a point of no return for relations between ethnic groups can usefully be seen as measures in the lineage of welfare schemes that had begun during colonial rule.

\section{I - The policy of standardisation and district quota in the university system: making a majority}

As a result of free education, by the late 1960s Sri Lanka had achieved near-universal literacy. In order to widen opportunities, university education was made available in the Sinhala and Tamil languages starting in 1959, resulting in a tripling of enrollments. Inequalities did not however disappear. A recent study has pointed out that 'the change in instructional languages and the expansion of the university system benefited the rural Sinhala Buddhist in quantitative, but not in qualitative terms ${ }^{168}$. Sinhala students were still under represented in the science programs that offered better prospects for employment unlike social studies and humanities courses.

In a country where in 1970 only 1 percent of young people in the relevant age category gained entry to universities there was tremendous social prestige and immense social mobility attached to entering university especially in the fields of engineering and medicine. The country offered a contrasting picture in terms of the quality of secondary schools which impinged on the students' results at the university entrance exam. There were clear regional imbalances with secondary schools concentrated along the South West coast (mainly inhabited by Low country Sinhalese) and in the Jaffna peninsula (peopled by Sri Lankan Tamils). In contrast the Kandyan Sinhalese who lived chiefly in the interior and the Moors (the term given for Muslims in Sri Lanka) many of whom lived on the east coast or were scattered in other parts of the island had poorer access to secondary education.

Until 1960 all university admission examinations had been in English thus lessening the likelihood of favouritism for students of various ethnic groups. When the medium of instruction in secondary schools changed from English to Sinhala and Tamil the number of students enrolled in secondary schools grew at a phenomenal rate. Two new universities were created to meet the demand for university education. Expansion in the universities was mainly confined to the arts and humanities, while much of the competition

\footnotetext{
${ }^{5}$ Asoka Bandarage, The Separatist conflict in Sri Lanka. Terrorism, ethnicity, political economy, Colombo: Vijitha Yapa Publ. 2009, p. 53.
} 
was to enter science based courses. In the 1970 s over 70 percent of schools in Sri Lanka that prepared students for the Grade 12 examination had no science classes up to that level.

Apart from regional disparities, there were also imbalances between ethnic groups. Tamils as a group performed better in science subjects at the university test. There were a number of reasons for this: higher literacy in English, more extensive facilities for science teaching in Jaffna, and motivation to study science in an area where other options for employment were not present. As a group that formed 12 percent of the population, Sri Lanka Tamils had in 1970 gained 35.3 percent of admissions to science based courses, including 40.8 percent of the places in engineering and 40.9 percent of the places in medicine ${ }^{169}$.

\section{Schemes}

Scholars are divided on the reasons that led to the introduction in 1970 of a form of affirmative action for university admissions and have rarely addressed except in a very superficial manner the effects of these policies on collective identities in Sri Lanka. The main problem is the complexity of the schemes that were brought about which led to confusion in peoples' minds as to their motives and the manner in which politicians modified them throughout the 1970s to suit the demands of pressure groups.

Rumours appear to have initiated the first foray into affirmative action for the majority community. In 1970 the belief spread before university admissions were announced that 60 percent of the admissions to the engineering faculty would be Tamil students. It was alleged that the high figure was due to over-marking on the part of Tamil medium examiners. In spite of an investigation revealing that there was nothing to substantiate the allegation, pressurized by a militant group called the Sinhala Tharuna Sanvidhanaya (the Sinhalese Youth Organization) the United Front government made the controversial decision to admit students to science based courses on the basis of predetermined minimum mark levels applicable

\footnotetext{
${ }^{6}$ Chandra Gunawardena, 'Ethnic Representation, Regional Imbalance and University Admissions in Sri Lanka', Comparative Education, Vol. 15, No. 3, Special Number (4): Disparities and Alternatives in Education (Oct., 1979), p. 301-312; Prasantha Herath, Kamala Liyanage, Morikazu Ushiogi and Hiromitsu Muta, 'Analysis of Policies for Allocating University Resources in Heterogeneous Social Systems: A Case Study of University Admissions in Sri Lanka', Higher Education, Vol. 34, No. 4 (Dec., 1997), p. 437-457; CR de Silva, 'The Impact of Nationalism on education: the schools take-over (1961) and the university admission crisis 1970$75^{\prime}$ in R.B. Goldman and A.J. Wilson eds. From Independence to Statehood: Managing Ethnic conflict in five African and Asian states, London 1984; 'Weightage in university admissions, standardization and district quotas in Sri Lanka', Modern Ceylon Studies, 5 (2) 1974, p. 152-178; 'The Politics of University admissions. A Review of some aspects of admissions policy in Sri Lanka', Sri Lanka Journal of the Social Sciences 1 (2) 1978, p. 85-123, 'Sinhala-Tamil relations and education in Sri Lanka: the University Admissions issue. The First Phase, 1971-7', in From Independence to Statehood; K.M de Silva, 'University Admission and Ethnic Tension in SL: 1977-1982' in R.B. Goldman and A.J. Wilson eds. From Independence to Statehood.
} 
to the three language media in which students sat the examination ${ }^{170}$. The United Front government headed by Sirimavo Bandaranaike could take such bold steps as it had a 2/3 majority in parliament and had been elected without the support of minority groups. The measure was immediately criticized by academics as well as prominent Tamils but with little impact. The effect of the scheme was for example that in the case of admission to the Medical Faculty, the minimum mark for entry was set at 229 for the Sinhala medium while it was 250 for the Tamil medium. The same minimum marks were used for the English medium as well, depending on whether the student concerned was a Sinhalese or a Tamil.

This method of selecting students was, however, abandoned the very next year perhaps because the losses suffered by the Tamils as a group were marginal: even with the formula Tamils secured 34.7 percent in engineering and 39.3 percent in medicine as compared to 40.8 and 40.9 in 1970 . But what was important was the sense of alienation caused by the realization that political power had been used to discriminate against people of a particular ethno-linguistic group. This first scheme of affirmative action was clearly an ill-conceived and rushed response to racist allegations that Tamils were cheating by overmarking their own students. Its purpose was explicitly and unequivocally to limit what was described as the 'unfair' entry of Tamil students into science and medicine courses thus providing more space for Sinhalese medium students.

A year later a new scheme was put in place. The context is important. In April 1971 the government had come up against a youth revolt led by the Janatha Vimukthi Peramuna. Most of the participants were educated unemployed Sinhalese youth who felt that the education system was no longer playing its role in facilitating social mobility and providing access to elite ranks. A few months later after the revolt was quelled the government introduced a system of 'standardization' of the marks obtained at the GCE (A.L.) Examination, both in regard to subjects and in regard to language medium in which the student sat the examination. These 'standardized marks' were used as the basis for admission of students to the universities. The students were ranked on an all-island basis according to the 'standardized' marks and this order of merit was used as the criterion for admission up to the year 1974. 'Media wise' standardization was a device to reduce all marks to a uniform scale so that in the end the number qualifying from each language medium would be proportionate to the number sitting the examination in that medium. The implicit purpose was by neutralizing the superior performance of Tamil medium students in science subjects to reduce the alienation of the educated Sinhalese youth.

The final scheme is known as the district quota system. After officials realized that the language based standardization policy did not end the privileged status of urban students hailing from the more developed districts,

\footnotetext{
${ }^{7}$ Sansoni Commission hearings (International center for Ethnic Studies) 18/9/1978, Mr. Premaratne to Mr. Tennakoon.
} 
the government turned to a geographically based policy for university admission - the district quota system. Places in coveted university science programmes had been until then going largely to the more 'advanced' Western and Northern provinces which had facilities for science and English medium education. The provinces where the Kandyan Sinhalese were concentrated and amounted to 47 percent of the island's total population gained only 19 percent of places in science courses in $1973^{171}$. Like the Kandyans, the Moor/Malay groups also lagged behind in education. The Kandyans and the Muslims were influential in the UF government. Mrs Bandaranaike was herself a Kandyan and the minister of Education, Badi-uddin Mahmud, was the leader of the Islamic Socialist Front.

Critiques of the university admission schemes of the 1970s tend to focus exclusively on the first two experiments in social redistribution where the motives and aims were quite clearly to limit the entry of Tamils into coveted science programmes. The district quota system that followed must be subjected to a more complex scrutiny as it combined multiple aims that involved a social transformation that went far beyond rectifying ethnic imbalances: one crucial aim was to advance regional equality and increase the representation of the Kandyan areas, the Batticaloa area where Muslims were concentrated and the unrepresented rural areas in general. Furthermore under the district quota system a specific clause was introduced that looked at the district of birth rather than residence, thus allowing a greater number of university places for Muslims from 'backward' areas like the east. Muslim student numbers in science faculties doubled between 1970 and 1975.

\section{Effects}

The 1960s had witnessed the ascendancy in the Ministry of Education of a group of officials that firmly believed that some adjusting mechanism was necessary to give Sinhalese students a chance in competing for the coveted places in science base courses. After the 'media wise standardization' scheme was introduced in 1970 they argued that there was little change in the fact that the best jobs still went to the well-connected, English-speaking elite. District quotas were their answer to the sense of deprivation and disillusionment with the state that prevailed among youth of the Sinhala speaking communities. It was not aimed at depriving Tamil students but at evening out the playing field that had been until then monopolized by a 5 percent anglicized elite.

Other mechanisms could have been used to give Sinhalese students a chance in competing for the coveted places in science based courses. But the UF government instead of taking greater initiative to provide well equipped schools and English language facilities for science education to the backward areas took the seemingly easier route of reverse discrimination against privileged Tamils and urban Sinhalese. The scheme did not lead to social justice but to the construction of new elites among the majority population

${ }^{171}$ Bandarage, op. cit., p. 59. 
who challenged the supremacy of Colombo based anglicized social groups occupying all the coveted jobs in private sector firms through old boys' networks and family connections. The new rising social group selected on merit as well as weightage to the university system was culturally and socially different from the multi-ethnic elite that had come to power after independence. Its members who hailed mainly from Sinhalese speaking, rural or peri-urban areas resented the domination of the English-educated groups both Sinhalese and Tamils - and placed their faith in the transformative, corrective and redemptive powers of the state.

The district quota system did not fulfill its promises and proved in fact a double-edged weapon. Not only did it initiate a sharp deterioration in relations between Sinhalese and Tamils, but it proved to be divisive among the Sinhalese themselves. First it distorted the pattern of entry between urban and rural populations, between heavily populated low-country Sinhalese regions where competition for places was acutely felt, and thinly populated Kandyan areas, where the minimum marks for admission to the universities were so much lower than elsewhere. The district quota system did not benefit students from the most backward areas that lacked facilities in science education. For example predominantly Sinhala districts, such as Hambantota, Polonnaruwa and Moneragala could not take most of the places reserved for them in the science faculties due to lack of educational facilities. In the meantime, well qualified students from the 'advanced' areas were shut out due to the restricted quotas imposed upon them. Secondly it resulted in resentment against the Muslims in both Tamil and Sinhalese areas and contributed greatly to the series of clashes between Sinhalese and Muslims throughout the island in the mid-1970s, culminating in a serious anti-Muslim riot in Puttalam in 1975. Thirdly Sinhalese living in Kandyan areas benefited from the quotas that were swollen from the large numbers of Tamil residents who were not sufficiently qualified to vye for entry to the university.

If the aim of the standardization schemes was to attack urban elite privilege it was only a short term victory as anglicized elites would find in the open economy era that was to follow other options to educate their youth. A commissioner at the Sansoni Commission pinpointed the fundamental flaw in the standardization scheme: 'By standardization' he said 'you cannot remove disparities. It is a make shift remedy that needs to go along with strengthening lab facilities and increasing the capacity of teaching staff in deficient regions ${ }^{\prime 172}$.

If its implicit aim was to limit the entry of Tamils into science faculties, this aim at least was realized. For the Tamils from Jaffna the district quota system was a major blow. In 1974, the absolute numbers of Tamils entering the science faculties dropped for the first time, and in 1975 the percentage of Tamils in all the science faculties fell to an all-time low. This led to a feeling

\footnotetext{
${ }^{9}$ Sansoni Commission, 13/9/78, Mr. W.H.A. Wijeratne Banda, Registrar, Peradeniya University questioned by P. Thilagadas.
} 
of alienation among the middle-class youth of Jaffna who had few other options available.

\section{Revision of the scheme}

The opposition to the scheme was swift, vocal and strong, inevitably from the Tamils but also from Sinhalese in Low Country urban areas. Tamil elites mobilized Tamil youth discontent while Sinhalese elites opposed the system as iniquitous. Their pressure led to the revision of the scheme in 1976. The matter came up for discussion before the sectorial committee on social overheads, Mass media and Transport of the National Planning Council, a cabinet sub-committee. The sub-committee submitted its report early in Oct. 1975, recommending the abolition of media-wise standardization, and commenting adversely on the district quota system and the rationale behind it. It did not however take its criticisms to their logical conclusion. Eventually it recommended a complicated modification of the admissions system: 70 percent on 'raw marks' and 30 percent on the district basis, of which half or 15 percent was to be reserved for 'educationally backward areas'. The Sinhala Tharuna Sanvidhanaya (Sinhala Youth Organization) strongly opposed the changes with the support of a powerful group of bhikkus (monks). The modification of the university admissions policy introduced in 1975 brought distinct advantages to the Tamils and their share of admission to the science based faculties rose by 35 percent in 1975-76, with the total percentage rising to $25^{173}$. But among Tamils there was always the fear that other changes could be furtively introduced and the advantages obtained were not secure.

In 1977 - the last year of the UF government - the Tamil numbers and percentages in university science faculties improved significantly from the all-time low of 1975 although they did not reach the exceedingly high levels that had prevailed prior to 1970 .

The university admissions problem assumed such an importance in the years 1970-77 in regards to ethnic relations on the island that the abolition of standardization became an electoral pledge of the United National Party led by Junius Richard Jayawardena. It was one of the first policy decisions taken and announced after the 1977 victory of the UNP. The government reverted to the pre-1970 policy when the sole criterion was the aggregate of marks scored by the candidate. The context was ripe with tension: in August 1977 there had been ethnic riots and the return to the older system was met with many critics. The government then decided that though standardization had been abandoned all students who would have gained admission to the university had there been standardization should be admitted. Special consideration was given to students from districts which were 'underprivileged in terms of educational facilities'. To the initial 3700 students admitted on raw marks were added 900 others and subsequently 250 . This exercise in pragmatism brought advantages to everyone especially the

${ }^{173}$ K. M. de Silva, op. cit., p. 102. 
Tamil students entering science based courses. But many Sinhalese nationalists were unhappy with the 1978 compromise. Other formulas followed. In 1979-1980 the district quotas returned in a different form. In 1981 yet another formula increased the merit quota to 40 percent and the district quota to 60 percent $^{174}$. This system guaranteed opportunity for all ethnic groups in rough approximation to their population throughout the country.

But the harm was done. For a generation of Tamil youth, affirmative action schemes of the 1970 s constituted irrevocable evidence of the partiality of the state vis-à-vis the majority Sinhalese. Rev. Fr P.A.A. Casperz testifying before the Sansoni Commission appointed to investigate communal riots of 1977 made the important point that if people thought their grievances were real it was as good as if they were real:

'It is not easy for us to see how much of the Tamil sense of grievance is imaginary and how much of it is real. But I have no doubt that much of it is real, and something effective must be done to remove even the imaginary grievance $^{175 \text {, }}$

\section{II - The different shapes of social justice: from a colonial regime of entitlements to the spirit of reconquest}

The politics of university admissions that gave weightage mainly to sections of the Sinhalese community in an unusual exercise of affirmative action towards a majority community can be traced to the policy of ceylonisation of the public service that began in the $1930 \mathrm{~s}$ and to the commitment to welfarism that was borne out of the Fabian inclinations of the men who drafted the Donoughmore Constitution of 1931. More crucially the premise of the standardization/district quota scheme was the idea of distinctness, boundedness of cultures, a fact often taken for granted. Colonial rule in many ways had entrenched the principle that different communities were entitled to different degrees of rights, dues and representation according to criteria that varied in time. In Sri Lanka it was ethnicity that became the defining feature of group belonging rather than religion or caste. By the end of colonial rule, the state recognized and worked through clearcut categories: Sinhalese (Low-Country and Kandyan), Ceylon Tamils, Indian Tamils, Moors, Burghers. In 1931 however, the principle of communal representation was denounced as a 'canker' and abolished. Later, with universal suffrage and the newly independent state's commitment to welfarism, the citizen was bestowed with certain privileges such as free education and free health services. More than through rights given by the constitutions it was through welfare entitlements than people imagined themselves as part of a social order and were able to conceive themselves as citizens.

\footnotetext{
${ }^{174}$ Report of the Committee appointed to review university admissions policy, UGC, Sri Lanka, Dec. 1987.

${ }^{175}$ Sansoni Commission Hearings, 5/6/1978, testimony of Fr Caspersz.
} 


\section{Ceylonisation}

Two of the minorities in Sri Lanka had contributed large numbers of personnel to the administrative service from the 1870 s through to the 1920 s, mainly because of their higher proficiency in written English ${ }^{176}$. Burghers (people of mixed descent who could trace their ancestors to Dutch or Potuguese) occupied many staff positions in technical departments, particularly the medical and Public Works Department and clerical positions in the Customs department.

During the two State Councils elected in 1931 and 1936, a transfer of power of a sort occurred in the administration. This has been described as a ceylonisation programme. The premise of this policy is that that the state has a right and authority to construct a fairer and more representative public service in the context of a multi-ethnic society still ruled by Europeans. For instance, in the civil service in 1930 there were eighty three Europeans and fifty-five Ceylonese. Ten years later there were only forty nine Europeans to eighty one Ceylonese. The proportion of Ceylonese in the Public Service increased from 68.1 in 1934 to 78 percent in $1939^{177}$. The 1930 s witnessed a gradual change in the share of administrative jobs between the various communities. By 1946 the under-representation of the Sinhalese in the higher administrative service had been nearly corrected and there were sixtynine Sinhalese, thirty one Tamils and sixteen Burghers. In other areas Ceylon Tamils and Burghers were still overrepresented, although the numerical superiority of the Sinhalese was evident. This was due to the change in the English literacy rate for the whole population, and a consequent higher output of English educated people among the Sinhalese as opposed to the Tamils and Burghers. Possibly many Sinhalese turned to employment in the public service as a result of economic trends in the 1930s. Indeed the Sinhalese sector of the elite had been more seriously affected than others because its stake in the plantation had been greater. Evidently this rectification was resented by members of the Tamil and Burgher communities. This issue was occasionally raised by A. Mahadeva in the State Council. Just as often Sinhalese members protested against cases of favouritism towards Ceylon Tamils by selection committees. Muslims too complained about the State Councils' neglect of the minorities. The 1930s witnessed a change in the relations between elite members of different communities. Allegations of favouritism, discrimination and canvassing were now made openly and this sowed the seeds of future tensions between the political elites ${ }^{178}$. Similar

\footnotetext{
${ }^{13}$ For a critical appraisal of 'divide and rule' policies see Nira Wickramasinghe, 'David and Rule in Ceylon (Sri Lanka during the period of transfer of power', University of Ceylon Review, Vol. 10, Dec. 1991, p. 75-92.

${ }^{14}$ S.J. Tambiah, 'Ethnic Representation in Ceylon's Higher Administrative Services, 1870-1946', University of Ceylon Review, 2 and 3, April-July 1955; Government of Ceylon, Sessional Papers XVIII, 1939, p. 40.

${ }^{15}$ See Wiswa Warnapala, Civil Service Administration in Ceylon: A Study in Bureaucratic Administration, Colombo 1974; C. Collins, Public Administration in Ceylon, London, 1951, p. 99-100.
} 
types of rumours of Tamil dons overmarking Tamil students would circulate in the 1970s in university circles.

Ceylonisation was important as a normative device. In many ways this process gave acceptability to the principle that the state had a regulating role to play in the ethnic distribution of educational and other assets. It opened up the conditions of possibility for groups that felt disadvantaged to seek and demand redress on moral/ethical grounds.

\section{Colonial regime of entitlements}

The postcolonial state's regime of welfare entitlements grew out of the colonial state's policy of bestowing rights and privileges on targeted social groups. Unlike in its representation schemes based on ethnicity that lasted until 1931, the distribution of welfare did not ostensibly target one community, but focused on occupational groups such as the peasantry or social groups such as the poor or underprivileged. As early as the end of the nineteenth century some initiatives relating to labour welfare had been forthcoming motivated essentially by the need of the state to safeguard the highly profitable plantation sector by giving special treatment to indentured Indian labour. In 1927, for instance, minimum wage legislation was enacted for Indian estate labour.

The origins of welfarism can be more clearly traced to the Donoughmore Constitution years (from 1927 to 1947) when social legislation relating to a wide number of issues such as child and family welfare, poverty alleviation, education and health and social security was promulgated. The commitment to improving living standards through education and health policies surfaced in these transition years of semi-self-government as a concomitant of universal franchise. However the 1930s were particularly hard on the poorer sections of the population, as those years were further plagued by a severe drought and a devastating malaria epidemic. Thus it was necessity that sparked a number of measures - among them the Wedderburn Report of 1934 that led to the introduction of a Poor Law in 1939 - which attempted to deal with poverty by recommending state assistance, a measure that was not, however, continued in the years that followed. During the Second World War social welfare, except for a food subsidy for the entire population, was accorded little priority.

The Kannangara Report of 1943 recommended a system of universal and compulsory free education from kindergarten to university that led to a national system of education founded on the principle of equal opportunity. In practice, however, there were many discrepancies in the quality of education, and the resources invested therein, between Colombo schools and the rural schools.

The Jennings Report on Social Services had less progressive outcomes. It eventually led to a limited form of social security based employeremployee contributions, targeted only at the wage-earning public sector. The health services were covered by the Cumpston Report (1950) which led to the Health Services Act. The principle of the right to health care was set out, 
while private practice for doctors in the state sector was abolished. Another distinctive feature of the welfare state was involvement in public utilities such as transport ${ }^{179}$.

\section{Grievances and reparations}

Although the welfare schemes of the late colonial era appeared to be framed for all citizens, there were certain sectors that were identified as needing assistance based not only on economic factors but also for political reasons. The language of reparations was ushered in and continued throughout the 1950 s and 1960 s to culminate in the 1970 s with the university admission schemes. During the colonial period, peasant agriculture had been neglected as the British encouraged the import of Indian and Burmese rice. During the Donoughmore years, the Sinhala political class began to favour giving the peasant greater state assistance. The Donoughmore commissioners exemplified the new position of the late colonial state vis-à-vis the rural population conceived as in need of help and protection. The fact that the peasant represented the majority of the population was clearly stressed.

'It seems hardly necessary to observe that His Majesty's Government is the trustee not merely of the wealthier and more highly educated elements in Ceylon but quite as much of the peasant and the coolies and of all those poorer classes which form the bulk of the population ${ }^{180}$.'

The colonial state would take it upon itself to lead the rural sector into an era of prosperity where the differences between the urbanized elites and the rural folk would be bridged. The colonization of new land in the dry zone in the North east of the country from the 1930s onwards was very much aimed at ushering in a new era in peasant welfare, together with the avowed aim of increasing the production of paddy.

Chatterjee has argued that in the postcolonial state most inhabitants are only tenuously rights-bearing citizens. "As populations within the territorial jurisdiction of the state, they have to be both looked after and controlled by various governmental agencies, ${ }^{181}$. Indeed in Sri Lanka a few years after independence a Kandyan Peasantry Commission was formed under the chairmanship of N.E. Weerasooriya to inquire into the social and economic condition of the Kandyan peasantry in the Central and Uva provinces. The task of the postcolonial state was defined in no uncertain terms in a near millenarian language with regard to its most important citizens, the Kandyan peasants, who had been wronged by the colonial state: 'The hour has now arrived for adequate reparations ${ }^{, 182}$. At other times the language was one of

\footnotetext{
${ }^{16}$ This section draws from Nira Wickramasinghe, Sri Lanka in the Modern Age, chapter 8 'Sri Lanka: The Welfare state and beyond', London: C. Hurst 2006.

${ }^{17}$ Command papers 3131, Ceylon: Report of the Special Commission on the Constitution of Ceylon, July 1928, printed and published by His Majesty's Stationery Office, London, 1928, p. 32.

${ }^{18}$ Partha Chatterjee, 'Modernity, Democracy and a political negotiation of death', South Asia Research, 1999, 19, 103; for a more recent rendition of the argument see The Politics of the Governed, New Delhi: Permanent Black, 2004

${ }^{19}$ Ibid., p. 46.
} 
affirmative action where equal citizenship entailed more justice for some: 'Rehabilitation is a different process and requires special treatment and a different approach' ${ }^{183}$. The 'pastoral' function of government described by Michel Foucault which emphasized welfare and protection of populations was given a sharper edge with the naming of culprits: 'The peasant's main occupation is agriculture, but his holding is too small to permit him to earn his livelihood from its produce. He is ready to take subsidiary employment, agricultural or otherwise, but the avenue of employment on the plantations is blocked by Indian labour' ${ }^{184}$.

The postcolonial state was upholding the reading of the island as consisting mainly of a peasant economy disrupted through the impact of a plantation economy based on the exploitation of cultivable land for commercial purposes.

The university admission schemes of the 1970s that aimed at creating a meritocracy drawing in the children of the Sinhalese peasantry were the logical outcome of the transformative project of modernity that had floated freely since the 1930s, where the victims were the Sinhalese peasants and the culprits shifted from Indian plantation labour to anglicized elites of all communities. The Tamil youth however, read the schemes as directed exclusively at the Tamil community. Their anguish over the issue of university admissions stemmed from a sense of deprivation, the sense that the halcyon days of the late 1960s when Tamils dominated the science based faculties were lost. Most scholarly interpretations of standardization have eluded another possible reading of the schemes as an imperfect attempt at creating a more socially equitable university system, where the monopoly of the anglicized elites of all communities would be eroded. CR de Silva predictably castigated the entire project of social engineering without taking into account its contribution - albeit imperfect - to deepening democracy. 'It was an object lesson in how inept policy measures and insensitivity to minority interests can exacerbate ethnic tensions ${ }^{185}$. KM de Silva on the other hand draws a direct line between the university admissions reforms and the worsening of ethnic relations:

'Few issue have contributed more substantially and dramatically to the sharp deterioration of ethnic relations in Sri Lanka in the last decade, or radicalizing the politics of the Tamil areas in the north and east of the island than the question of university admissions ${ }^{186}$.

A more nuanced picture of the effect of standardization on ethnic relations has been painted recently by $\mathrm{R}$. Cheran who points out that the standardization schemes and district quotas generated very little interest in areas other than Jaffna and did not concern the Tamil masses especially the

\footnotetext{
${ }^{20}$ Ibid., p. 16.

${ }^{21}$ Ibid., p. 5.

${ }^{185}$ CR de Silva, p. 94, in ed. Goldman and Wilson.

${ }^{186} \mathrm{KM}$ de Silva, p. 95, in ed. Goldman and Wilson.
} 
peasant class who constituted in Jaffna more than half the population ${ }^{187}$. Standardization was very much an issue for the middle-class Tamils of Jaffna.

\section{Conclusion}

One interpretation of the 1970 s university admission reforms has censured the state position on democracy for aiming to consolidate an ethnodemocracy where policies were framed so as to protect the majority Sinhalese from encroachments by minority groups. While this reading is not totally fallacious it needs to be weighed against another possible reading which signals among administrators, legislators and officials the importance of ideas of social justice enshrined in politics of redistribution that transcended ethnicity. In the 1970s dominant liberal interpretations unilaterally endorsed the claims of Tamil youth and legislators for a return to a system where the unevenness of life chances of various communities and regions would not be factored in. The Tamil youth were fighting a losing battle for even without standardization there would have been a reduction in the percentage of places for Tamils in science based faculties due to the natural growth of literacy among the Sinhalese majority community. It is the manner in which attempts were made to force the pace of change that converted the university admission issue from a controversial educational problem to a complex emotionally charged political issue that lingered on even decades later. Indeed there was no public debate among intellectuals on the moral/ethical foundations of the schemes. As a result responses came as violent outbursts.

The failure of the state to guarantee social mobility through education and the unequal distribution of educations entitlements were central issues in the Southern insurrections and the Tamil insurrection in the North and East in the 1970s. While issues of unemployment led the Sinhala rural educated youth to rebel in 1971, the early Tamil militancy was energized by the issue of standardization. As Cheran sharply suggests this explains the middle class character of the early Tamil militancy in Jaffna which only in the late 1970s spread to less privileged social groups ${ }^{188}$.

The 1970s crisis illuminates how the lack of public debate on issues of equality of opportunity can lead to distrust and misinterpretations that still linger on. If a better case had been made for 'justice as fairness' and if minority communities had been made to accept that inequality is permissible as long as inequalities result in maximizing the position of the worst off in society and if the state had boldly condemned all excesses of the nationalist promoters of standardization in the admission to universities, these schemes would have led to a deepening of democracy rather than spawned feelings of betrayal by the once protective and caring state.

\footnotetext{
${ }^{24}$ Ed. R. Cheran, Pathways of Dissent. Tamil Nationalism in Sri Lanka, New Delhi: Sage Publishers, 2009, p. XXXIII.

${ }^{188}$ Ibid., p. XXXI.
} 